\title{
Editorial
}

\section{Roads towards a lingua democratica on genomics: How can metaphors guide us?}

Metaphors flower in all fields of science, and genetics and genomics are no exception. No sooner had the structure of DNA been established than it was described as the book of life, the holy grail of biology, the program of development, the blueprint of who we are, etcetera. The metaphors overwhelmingly expressed the idea that DNA is basic to an understanding life and that it determines the characteristics of living beings. But such views led to neglect for non-genetic causes in biology. By the time gene-centric metaphors caught attention as metaphors, they were quickly criticized as being too one-sided, deterministic and reductionist. In order to do more justice to interaction, regulation, epi-phenomena and chaos, many new metaphors appeared: the genome is a recipe, a network, a jazz orchestra, the servant of proteins. The assault on DNA's biological hegemony has even gone to metaphorical extremes in which it is a garbage bin, or a dusty attic full of old and forgotten stuff.

Though this picture is just a quick snapshot, it illustrates two phenomena of metaphors in the context of genetics: there are many of them, and they are contested. This special issue of Genomics, Society and Policy takes these basic facts as a starting point for its explorations. The issue is one of the outcomes of a larger research project on the question of how open and democratic exchange on genomics between heterogeneous groups can be enhanced. ${ }^{1}$ Rather than favouring a lingua franca (for which the call for project proposals had asked), our project set out to contribute to a lingua democratica: we wanted to recognize differences rather than eradicate them, and were looking for 'horizontal connections' between local languages, including "fruitful frictions". One subproject focused on metaphors: how can they hamper democratic dialogue, how can they help? ${ }^{2}$

In a search for answers, two different directions can quickly be recognized: first, a search for the most helpful metaphors; and second, an emphasis on the importance of a plurality of metaphors. Although these options are not at all mutually exclusive, they start from different assumptions about the way in which metaphors matter. The assumption that guides the first route is that we need rich and inclusive ways of seeing in all domains of thought. Metaphors are ways of seeing, theories are built on them, and some metaphors are so narrow or inadequate that we should drop the theories as well as their metaphorical frames, and move on to better ones. Strengthening pluralism, the second direction, starts from the idea that what primarily makes metaphors problematic for democratic exchange is not inadequacy, but self-evidence. We need a vital plurality of ways of seeing to remain aware of the limitations of each of them. In our subproject, we favoured the second road. One of the main lessons from the omnipresence of metaphors is that all metaphors afford a selective view. This applies to blueprints, recipes, networks and dusty attics alike, and if this is so we centrally need what Schön and Rein have called dual vision: ${ }^{3}$ the ability to see the point, the value, and the advantage of other limited ways to look at the world, even if

Genomics, Society and Policy, Vol.5, No.3 (2009) ISSN: 1746-5354

(C) ESRC Genomics Network. 
we don't agree. This ability is an important aid not only to safeguard us from the reification of our own views, but also for fruitful frictions in debate. Fully discarding a metaphor that was formerly thought to be perfect in order to fully embrace its even more perfect successor comes down to throwing away the baby with the bath water.

In the call for papers for the final conference of the project, we characterized the multiplicity of metaphors on genomics as a thicket. ${ }^{4}$ We announced that we did not see the diversity and variety of plants in the thicket as an obstacle to a lingua democratica, and that we were not asking to eradicate any plants. The challenge was rather how to domesticate the thicket while cherishing its diversity, and benefit from it. Turning to different metaphors: diversity and friction may well count as cooperation from a democratic point of view, as they enable us to avoid the worst hypes and blind spots in how we frame our debates. ${ }^{5}$ As the above makes clear, we operated in an area between science and society. Many of our discussions focused on metaphors that originate in science. But we did not look at these metaphors as biologists who were looking for a way to frame our research questions. The normative emphasis on pluralism stems from a societal outlook and from our emphasis on democracy. As a consequence of this outlook, the authority of metaphors stemming from science is a theme of reflection.

Even apart from any democratic call for pluralism, normative evaluation of particular metaphors in the thicket is a more thorny task than has often been thought. The main reason is that the use and interpretation of metaphors is not at all as straightforward as many metaphor researchers initially took for granted. Meanings and interpretations are not simply transported from source domain to target domain, but turn out to be context-dependent in many ways. For example, Celeste Condit's audience studies have shown that the blueprint metaphor, much maligned because of its assumed determinism, can be interpreted in very different ways, depending on personal associations and on context. On the one hand, the blueprint metaphor is often interpreted as a plan with fixed characteristics. But others see it as an open, nondeterministic plan that can always be adapted. ${ }^{6}$ Such different and contextual interpretations are not a peculiarity of the general public; they occur equally among metaphor researchers. Leah Ceccarelli writes that she had always taken the map metaphor to be deterministic, in comparison with the more open blueprint metaphor. ${ }^{7}$ She describes her surprise at the indeterminist interpretation of the map metaphor at the press conference at the White House in 2000 which announced the completion of a first draft of the human genome. The genome was presented there as a map that allowed very new expeditions, a map that does not determine the territory but opens it up to exploration and conquest, in short, to alteration. In contrast to Ceccarelli, Hub Zwart began by interpreting the map metaphor as less deterministic than the blueprint metaphor. ${ }^{8}$ He was in for different surprises in the 2000 White House Press conference, which he describes in his article in this special issue (see p. 28).

Multiple interpretation is completely general, it extends to all metaphors. Maps, and the related metaphor of journey, are rewarding examples, because they are used in very many domains and with very different connotations. A paper by Milne et al may serve to point up some of the selectivity as well as the flexibility of journeys. ${ }^{9}$ When 
corporations set out to become more sustainable, they often use the journey metaphor to emphasize that the road will be long, exciting and open-ended, and that it is far too early to specify a final destination. Because of this lack of destination, Milne et al criticize the journey metaphor as being too noncommittal. It allows corporations to sound exciting and daring, while in fact they continue business as more or less usual, using their small first steps to distract from thoughts of radical transformation. The authors therefore argue that the journey metaphor will not do and that metaphors of transformation are needed. Yet the example suggests that a journey with a destination might work as well; a completely different metaphor is not always needed to picture a different reality. The example also illustrates that what is left out (here, final destinations) can be as illuminating as what is included. ${ }^{10}$ The use of map and journey metaphors in the world of computer games is another example of the constant change of metaphors, this time precipitated by technological innovation. In the world of computer games, journeys often take place directly on virtual maps, with wide open opportunities for altering them. In these games, map-making and travelling are often intimately interwoven; the players are mastering the world through interactive cartography, and this merging adds new connotations to both travelling and mapmaking, adding new members to the already huge set of possible interpretations. ${ }^{11}$

All the authors in this special issue were invited to reflect on how to deal with the thicket of metaphors in social contexts of genomics. Let me introduce the papers, specifically focusing on the question whether and how each of the papers proposes to be normative with regard to metaphor.

Eric Juengst and John Huss tell the fascinating story of how the "metagenome" has come into being. Metagenomic analysis started as a way to bypass the problems of studying the genomes of the myriad microbes in soil: simply sequence them en masse. The enormous fruitfulness of this bulk sequencing approach has been transferred to other areas, such as the human body, with the result that our identities have now changed: each of us is an ecosystem, or rather a set of ecosystems, encompassing trillions of microbes that inhabit all our surfaces, internally and externally. The authors emphasize that new ways of looking often originate in new tools, in this case metagenomic analysis, and that a new entity, here the metagenome, may be the reified result of such tools. Among the different interpretations and implications of this new entity, many of which still have to emerge, they call attention to interesting changes in our sense of who we are. At the same time, they see potential new reductionisms, in which the newly discovered ecosystems are being reduced to their genetic sequence. In order to strengthen approaches that do justice to complexity, they advocate that social sciences and humanities should be involved in translating the messages of microbiomics.

Brendon Larson directly and explicitly addresses the themes of the conference in his paper on fruitful frictions versus unfruitful fictions. Differentiating between epistemic (scientific) and social realms, he argues for the many benefits of metaphoric plurality in science as well as society. Metaphors as a prophylactic against reification are prominent among the benefits in the epistemic realm. In the social realm, he argues for the need to counteract the privileged position of scientists, whose metaphoric 
descriptions are prone to quick transformations from scientific is to social ought, transformations that are stimulated by the implicit values hidden in these metaphors. As an example, he discusses the metaphor of the 'human journey', which is the dominant metaphor associated with the Genographic Project, the reconstruction of the geography of human history through genomic analysis. The journey metaphor is problematic, he says, because it creates the vision that we are all one, while neglecting the diversity of alternative life stories. We need alternative pictures that celebrate diversity, he argues. Because of the need to 'counterbalance' the social influence of science, the call for metaphoric plurality is not enough, according to Larson. A call for metaphor choice in a larger democratic context needs to be added. Flexibility for choice is greatest in the upstream phases, where an engagement between science and society could do much good, but the decision if and when to intervene must be a democratic decision itself.

Hub Zwart focuses on the map metaphor, and more precisely on its role in the presentation of the first draft of the human genome, at the 2000 press conference at the White House. A whole sequence of genomics metaphors were used at this occasion, but the map metaphor won the day to the point of being adored in an atmosphere of religious awe. President Clinton strikingly introduced the map image by reminding the audience of the famous map of Lewis and Clark, which was the product of their pioneering frontier expedition to the West. The speakers at the press conference announced that the map of the human genome would likewise open up new territory, and create opportunities for new discoveries, campaigns, advances and conquests. These vistas illustrate that maps are not simply about objects but also about our relation to them; the Lewis and Clark map was very much about the ownership of the land, and the introduction of the human genome map took place in a similar property-oriented atmosphere. Zwart finds such possessive powerplay problematic. Still, it is in line with his reading of the map as an indeterministic metaphor, which puts the fate of the human genome in the hands of the people who will use the map and 'settle' in the mapped areas. Maps imply openness and promise and they therefore encourage us to focus on new possibilities rather than on predetermined fate. However, the actual use of the map metaphor is 'polluted', he warns, by remnants of older, more static and deterministic metaphors.

Celeste Condit's journey, in "Dynamic feelings" has a novel direction and a clear goal. Starting from a situation which she diagnoses as being overwhelmingly rationalist, her final destination is a full recognition of the importance of emotions, not only in the understanding of metaphor but also in policy. She demonstrates the importance of emotions in the appreciation of metaphors with the help of two experiments, in both of which people with only a modest amount of education were interviewed on genomic metaphors. Emotions are prominent in the findings of the first experiment and in the interpretation of the second. For example, in a context of disease causes, genes were often seen as viruses. In her interpretation, Condit writes that this is not as illogical as we might think; we can understand it by realising that people feel a gene to be a hidden threat - just like a virus. As a tentative underlying account, she proposes that metaphor search is activated by feelings. If you feel threatened, you will look for images that have the same feeling, and the image of a 
virus seems to roughly match up. These findings fit in with evolving views of human cognition as deeply embodied and emotional. Such a "biosymbolic" perspective presents many challenges for policy, including policy on genomics, which is now overwhelmingly framed in rationalist terms. Condit argues that the biosymbolic perspective urges us to pay attention to emotions, to report on actual emotional experiences and to look for ways to build on them in productive directions.

Finally, Cor van der Weele and Jozef Keulartz focus on views of innovation and ethics in which genomics research is embedded. We distinguish six metaphorical 'heroes' of innovation in agriculture, celebrating their multiplicity. But the heroes do not constitute a sparkling innovation club, since some heroes are constantly celebrated, while others are unsung and unseen. The over-dominant hero of innovation is the pioneering frontier man who, through frontier technology, confronts the dangers of the unknown wilderness and opens up unexplored territories. Craig Venter is the prototype of such a hero. Such heroes have traditionally been aided by wives who take it upon themselves to guard the safety of the home and protect moral and cultural values. In the context of genomics, this role is metaphorically fulfilled by ELSI. But there are more heroes of innovation: playful and artistic urban gardeners, subversive poor farmers, pragmatic innovation experts, and people who cultivate deep relationships with nature. They all deserve more recognition. Although some of these innovators seem to be anti-technological, technology does not emerge as the central underlying issue. Empowerment in the world of daily life and the quality of food, nature and public space emerge as more prominent motives. We argue that the heroes travel very diverse paths to the future, which cannot be understood by dichotomous distinctions.

Metaphors cannot be escaped on any level. In this introduction, I not only described the multiplicity of genomic metaphors as a thicket, I also suggested that metaphors guide us in how to deal with that thicket: should we clear a path through it, should we domesticate it, and if so, how? The idea that the variety of plants in the thicket is not optimal can be found in various papers. Juengst and Huss, Larson and Zwart all consider the ongoing influence of metaphorical determinism and reductionism as worrisome. Weeding out problematic metaphorical sprouts when they are still small (or, in a different metaphorical frame, in an upstream phase) is one option, suggested by Larson as well as by Juengst and Huss. Keulartz and I argue that the composition of the thicket should rather be enriched through loving care for young sprouts of vulnerable species. According to Condit, radically new criteria are needed to judge the value of plants: if we recognize the importance of emotion, we will learn to appreciate plants that we used to consider as useless weeds.

From a democratic perspective, it is a limitation of this special issue that we all approach the thicket from more or less the same perspective: as humanities researchers. Though our sympathy for diversity aims to create room for a variety of views, the need for weeding, caring, or re-appreciating is the need as we see it, not as it is seen by scientists or business people, for example. The limitation should make us modest about the range of views we introduce, and the possibly fruitful frictions between them. Yet, paying attention to metaphors has something inherently 
"democratic" when it comes to dominant and self-evident views. The discovery of their metaphorical character creates cognitive and emotional distance; ${ }^{12}$ some emptiness begins to surround them. They also start to shrink a little. And these bits of magic result in more room for other plants in the thicket.

Cor van der Weele

LEI, Wageningen University and Research Centre

\footnotetext{
${ }^{1}$ The title of the project was 'Towards a lingua democratica for public debate on genomics'. It was subsidized by the Netherlands Organization for Scientific Research (NWO). The project leaders were Professor Peter Derkx and Professor Harry Kunneman, both of the University of Humanistics in Utrecht, the Netherlands. I thank them for the kind invitation to take part in the project and for the fruitful cooperation.

${ }^{2}$ The other parts of the project will be explored in a book edited by Harry Kunneman and Peter Derkx. Its working title is Genomics and democracy: towards a 'lingua democratica' for the public debate on genomics.

${ }^{3}$ D.A. Schön, M. Rein. 1994. Frame Reflection. New York, Basic Books

${ }^{4}$ This metaphor has also been used for visual representation: "the thicket of representation" was coined by William Wimsatt and is discussed by James Elkins: J.Elkins. 2007. Visual practices across the university. München, Wilhelm Fink.

${ }^{5}$ C. van der Weele. Moral Agendas for Genomics: How to Find the Blind Spots. Configurations 2008; 16(1): 117-136

${ }^{6}$ C. Condit. How the Public Understands Genetics: Non-deterministic and Non-discriminatory Interpretations of the "Blueprint" Metaphor. Public Understanding of Science 1999; 8: 169-180. C. Condit. Recipes or Blueprints for our Genes? How Contexts Selectively Activate the Multiple Meanings of Metaphor. Quarterly Journal of Speech 2002; 88: 303-325.

${ }^{7}$ L.Ceccarelli. Neither Confusing Cacophony Nor Culinary Complements. Written Communication 2004; 21: 92-105.

${ }^{8}$ H. Zwart. 2009. Genomics Metaphors and Genetic Determinism. In New Visions of Nature: Complexity and Authenticity. J. Keulartz, M. Drenthen, J.Proctor, eds. Dordrecht, Springer: 155-172.

${ }^{9}$ M.J. Milne, K.Kaerins, S.Walton. Creating Adeventures in Wonderland: The Journey Metaphor and Environmental Sustainability. Organization 2006; 13: 801-839.

${ }^{10}$ In general, what is absent is harder to detect than what is present; it requires more cognitive distance, and some idea of what is missing. See also notes 5 and 12.

${ }^{11}$ S. Lammes. Playing the World: Computer Games, Cartography and Spatial Stories. Aether 2008; 111: 84-96.

${ }^{12}$ The notion of cognitive distance stems from Stephen Pepper. Seeing a metaphor as a metaphor creates cognitive distance, and this in turn creates room for alternative ways of seeing. See S.Pepper. Metaphor in philosophy. The Journal of Mind and Behaviour 1982/3: 197-206.
} 